\title{
Atrial fibrillation: a geriatric perspective on the 2020 ESC guidelines
}

\author{
M. Cristina Polidori ${ }^{1,2} \cdot$ Mariana Alves $^{3,11,12} \cdot$ Gulistan Bahat $^{4} \cdot$ Anne Sophie Boureau ${ }^{5} \cdot$ Serdar Ozkok ${ }^{4}$. \\ Roman Pfister ${ }^{6} \cdot$ Alberto Pilotto $^{7,8} \cdot$ Nicola Veronese $^{9} \cdot$ Mario Bo $^{10}($ D . on behalf of the Special Interest Group \\ "Cardiovascular Diseases" of the EuGMS
}

Received: 29 April 2021 / Accepted: 3 July 2021 / Published online: 2 November 2021

(c) The Author(s) 2021

\section{Key Summary Points}

Aim To provide a geriatric perspective on the 2020 ESC Guidelines for the diagnosis and management of atrial fibrillation developed in collaboration with the European Association of Cardio-Thoracic Surgery (EACTS).

Findings While the large majority of AF patients in real life are older, frail and cognitively impaired, these are mostly excluded from clinical trials, and physicians' attitudes often prevail over standardized algorithms. On the basis of existing evidence, we suggest that (1) opportunistic AF screening by pulse palpation or ECG rhythm strip is cost-effective, and (2) whereas advanced chronological age by itself is not a contraindication to AF treatment, a Comprehesive Geriatric Assessment (CGA) including frailty, cognitive impairment, falls and bleeding risk may assist in clinical decision making to provide the best individualized treatment.

Message The integration of CGA might positively influence clinical decision making in older patients with atrial fibrillation.

\begin{abstract}
Background The Task Force for the diagnosis and management of atrial fibrillation (AF) of the European Society of Cardiology (ESC) published in 2020 the updated Guidelines for the Diagnosis and Management of Atrial Fibrillation with the contribution of the European Heart Rhythm Association (EHRA) of the ESC and the European Association for Cardiothoracic Surgery (EACTS).

Methods and results In this narrative viewpoint, we approach AF from the perspective of aging medicine and try to provide the readers with information usually neglected in clinical routine, mainly due to the fact that while the large majority of AF
\end{abstract}

M. Cristina Polidori

maria.polidori-nelles@uk-koeln.de

1 Ageing Clinical Research, Department II of Internal Medicine and Center for Molecular Medicine Cologne, University of Cologne, Faculty of Medicine and University Hospital Cologne, Kerpener Str. 62, 50937 Cologne, Germany

2 Cologne Excellence Cluster On Cellular Stress-Responses in Aging-Associated Diseases (CECAD), University of Cologne, Faculty of Medicine and University Hospital Cologne, Cologne, Germany

3 Serviço de Medicina III, Hospital Pulido Valente, CHULN, Lisbon, Portugal

4 Department of Internal Medicine, Division of Geriatrics, Istanbul Medical School, Istanbul University, Capa, 34390 Istanbul, Turkey

5 Department of Geriatrics, CHU Nantes and Université de Nantes, CNRS, INSERM, l'Institut du Thorax, 44000 Nantes, France
6 Department of Cardiology, University of Cologne, Faculty of Medicine and University Hospital Cologne, Cologne, Germany

7 Department of Geriatric Care, Orthogeriatrics and Rehabilitation, Galliera Hospital, Genoa, Italy

8 Department of Interdisciplinary Medicine, University of Bari, Bari, Italy

9 Geriatric Unit, Department of Internal Medicine and Geriatrics, University of Palermo, Palermo, Italy

10 Section of Geriatrics, Department of Medical Sciences, University of Turin, A.O.U. Città della Salute e della Scienza, Molinette, Corso Bramante 88, 10126 Turin, Italy

11 Laboratory of Clinical Pharmacology and Therapeutics, Faculdade de Medicina, Universidade de Lisboa, Lisbon, Portugal

12 Instituto de Medicina Molecular, Faculdade de Medicina, Universidade de Lisboa, Lisbon, Portugal 
patients in real life are older, frail and cognitively impaired, these are mostly excluded from clinical trials, and physicians' attitudes often prevail over standardized algorithms.

Conclusions On the basis of existing evidence, (1) opportunistic AF screening by pulse palpation or ECG rhythm strip is cost-effective, and (2) whereas advanced chronological age by itself is not a contraindication to AF treatment, a Comprehensive Geriatric Assessment (CGA) including frailty, cognitive impairment, falls and bleeding risk may assist in clinical decision making to provide the best individualized treatment.

Keywords Atrial fibrillation $\cdot$ Advanced age $\cdot$ Older patients $\cdot$ Anticoagulation $\cdot$ Cognitive impairment

\section{Introduction}

The Task Force for the diagnosis and management of atrial fibrillation (AF) of the European Society of Cardiology (ESC) published in 2020 the updated Guidelines for the Diagnosis and Management of Atrial Fibrillation with the contribution of the European Heart Rhythm Association (EHRA) of the ESC and the European Association for Cardiothoracic Surgery (EACTS) [1]. As the authors state in the preamble "(...) The complexity of AF requires a multifaceted, holistic and multidisciplinary approach to the management of AF... with the goal to further improve the structured management of AF patients, promote patient values, and finally improve patient outcomes... the Task Force includes cardiologists with varying subspecialty expertise, cardiac surgeons, methodologists and specialist nurses amongst its members (...).". Reflecting the composition of the panel, this holistic "ABC strategy (A: anticoagulation/avoid stroke, $\mathrm{B}$ : better symptom control, $\mathrm{C}$ : detection and management of cardiovascular risk factors and concomitant diseases)" includes several developments with respect to the 2016 ESC guidelines [2], mainly focused on drug therapies (Table 1).

While the critical role of the ESC guidelines for the management of $\mathrm{AF}$ is out of the question, from a geriatric perspective such "holistic approach" comes short to address the complexity of older AF patients. Due to the nature of the aging process, in fact, there are crucial characteristics of older patients that, if neglected, often undermine, sometimes nullify the most perfect organ-centered treatment plan. These include multifactoriality, heterogeneity, atypical disease presentation, geriatric cascade, frailty just to mention a few. The appropriate use of the tools of geriatric medicine allows to balance the net clinical benefit of screening and therapeutic decisions and might be most appropriately shared and used in a meaningful interdisciplinary comanagement. On behalf of the Special Interest Group "Cardiovascular Diseases" of the European Geriatric Medicine Society (EuGMS), the aim of this overview is the disentanglement of age-related complexity by discussing specific questions arising in advanced age such as screening for AF, interplay with frailty, cognitive impairment, functional loss and falls. Furthermore, physicians' attitudes and uncertainties in prescribing oral anticoagulant therapy (OAT) will be addressed.

\section{Atrial fibrillation in advanced age}

Age is an independent risk factor for the development of AF $[3,4]$. In 2010 , the number of older individuals ( $\geq 75$ years old) with AF in the European Union was estimated to be 5.6 million, but this is expected to double to 13.8 million by 2060 , when subjects aged $80+$ years will represent $65.2 \%$ of total AF cases in European Union [1, 5]. The relationship of AF with increased risk of thromboembolism, stroke and mortality is well-established [3]. Patients with AF exhibit increased hospitalizations due to stroke, heart failure, need for pacemaker implantation and adverse effects related to anticoagulant and antiarrhythmic therapy. In addition, there are other known specific, but often overlooked problems closely related to AF in this population, including cognitive impairment with and without dementia, frailty, decline in physical performance and loss of independence [6-8].

"Older people" include a very heterogeneous group of individuals, varying from independent and robust persons to dependent and very frail ones [9]. Age-related physiologic changes (low body mass index, altered body composition of muscle and fatty tissue), multimorbidity and polypharmacy (with high frequency of renal impairment, altered pharmacokinetic profile of drugs and high risk of drug-drug interactions), frailty, cognitive impairment and functional limitations and life-expectancy are factors that should be taken into account in clinical decision making [9]. In such a complex population, not suitable to general recommendations, the correct clinical approach is essential to offer the best medical care and, at the same time, to avoid harm and futility [8-10]. Although guidance exists for inclusion of older patients in clinical trials [11], these are still underrepresented in randomized clinical trials (RCTs), whereas the most robust, independent and cognitively intact older patients fit are usually enrolled [12]. Although the Comprehensive Geriatric Assessment (CGA) and frailty measurement tools have been recommended to help guide decisions about AF anticoagulation in older patients [13, 14], this is not generalized in clinical trials nor current practice yet.

As a matter of fact, older patients represent the largest majority of those with AF [1]. Notwithstanding, most recommendations, including the recent 2020 ESC guidelines for AF management, stem from RCTs poorly representative 
of real-world older people, and come short to deal with the complex health characteristics of these patients [15].

\section{Challenges of atrial fibrillation in real life}

\section{Screening}

In addition to increasing prevalence of clinical AF with advancing age, a significant number of older individuals do not show any symptoms despite going through an episode of AF [16]. Unfortunately, asymptomatic (silent) $\mathrm{AF}$ is independently associated with stroke and mortality to a similar extent compared to symptomatic AF [17]. It is estimated that $1.3 \%$ of the population aged $\geq 65$ have undiagnosed, largely asymptomatic AF [18]. Patients with incidentally detected AF treated with OAT have stroke rates similar to matched individuals without AF [19]. Furthermore, their adjusted stroke and death rates are reduced, compared with those who are not treated or are treated with aspirin alone [19]. This provides justification for AF screening in high-risk populations. Of note, the 2020 ESC Guideline for AF management strongly recommends opportunistic screening of AF by pulse taking or ECG rhythm strip in patients $\geq 65$ years of age [1].
Table 1 Changes in the ESC recommendations on atrial fibrillation, 2016-2020 [1, 2]. Mod. from [2]

\begin{tabular}{|c|c|c|c|}
\hline \multicolumn{4}{|c|}{ Changes in the recommendations } \\
\hline 2020 & Class $^{\mathrm{a}}$ & 2016 & Class $^{\mathrm{a}}$ \\
\hline \multicolumn{4}{|c|}{ Recommendations about integrated AF management } \\
\hline $\begin{array}{l}\text { To optimize shared decision making } \\
\text { about specific AF treatment option(s) } \\
\text { in consideration it I recommended } \\
\text { that: } \\
\text { - Physicians inform the patient about } \\
\text { advantages /limitations and } \\
\text { benefit/risks associated with } \\
\text { considered treatment option(s); and } \\
\text { - Discuss the potential burden of the } \\
\text { treatment with the patient and include } \\
\text { the patient's perception of treatment } \\
\text { burden in the treatment decision. }\end{array}$ & 1 & $\begin{array}{l}\text { Placing patients in a central role in } \\
\text { decision making should be considered } \\
\text { in order to tailor management to } \\
\text { patient preferences and improve } \\
\text { adherence to long-term therapy }\end{array}$ & Ila \\
\hline \multicolumn{4}{|c|}{ Recommendations for the prevention of thrombo-embolic events in AF } \\
\hline $\begin{array}{l}\text { For bleeding risk assessment, a formal } \\
\text { structured risk-score-based bleeding } \\
\text { risk assessment is recommended to } \\
\text { help identify non-modifiable and } \\
\text { address modifiable bleeding risk } \\
\text { factors in all AF patients, and to } \\
\text { identify patients potentially at high risk } \\
\text { of bleeding who should be scheduled } \\
\text { for early and more frequent clinical } \\
\text { review and follow-up. }\end{array}$ & 1 & $\begin{array}{l}\text { Bleeding risk scores should be } \\
\text { considered in AF patients on oral } \\
\text { anticoagulation to identify modifiable } \\
\text { risk factors for major bleeding. }\end{array}$ & Ila \\
\hline $\begin{array}{l}\text { In patients on VKAs with low time in } \\
\text { INR therapeutic range (eg. TTR }<70 \%) \text {, } \\
\text { recommended options are: } \\
\text { - Switching to NOAC but ensuring } \\
\text { good adherence and persistence with } \\
\text { therapy; or }\end{array}$ & 1 & \multirow[t]{2}{*}{$\begin{array}{l}\text { AF patients already on treatment with } \\
\text { a VKAs may be considered for NOAC } \\
\text { treatment if TTR is not well controlled } \\
\text { despite good adherence, or if patient } \\
\text { preference without contraindications } \\
\text { to NOAC (eg. Prosthetic valve). }\end{array}$} & \multirow[t]{2}{*}{$\mathrm{IIb}$} \\
\hline $\begin{array}{l}\text { - Efforts to improve TTR (eg. } \\
\text { Education/conselling and more } \\
\text { frequent INR checks). }\end{array}$ & Ila & & \\
\hline \multicolumn{4}{|c|}{ Recommendations for rhythm control/catheter ablation of AF } \\
\hline \multicolumn{4}{|c|}{ AF catheter ablation after drug therapy failure } \\
\hline $\begin{array}{l}\text { AF catheter ablation for } \mathrm{PVI} \text { is } \\
\text { recommended for rhythm control } \\
\text { after one failed or intolerant class I or } \\
\text { III AAD, to improve symptoms of AF } \\
\text { recurrences in patients with: } \\
\text { - Paroxysmal AF, or } \\
\text { - Persistent AF without major risk } \\
\text { factors for AF recurrence, or } \\
\text { - Persistent AF with major risk factors } \\
\text { for AF recurrence. }\end{array}$ & 1 & $\begin{array}{l}\text { Catheter or surgical ablation should be } \\
\text { considered in patients with } \\
\text { symptomatic persistent or long- } \\
\text { standing persistent AF refractory to } \\
\text { AAD therapy to improve symptoms, } \\
\text { considering patient choice, benefit and } \\
\text { risk, supported by an AF Heart Team. }\end{array}$ & Ila \\
\hline \multicolumn{4}{|l|}{ First-line therapy } \\
\hline $\begin{array}{l}\text { AF catheter ablation: } \\
\text { - Is recommended to reverse LV } \\
\text { dysfunction in AF patients when } \\
\text { tachycardia-induced cardiomyopathy } \\
\text { is highly probable, independent of } \\
\text { their symptom status. }\end{array}$ & 1 & \multirow[t]{2}{*}{$\begin{array}{l}\text { AF ablation should be considered in } \\
\text { symptomatic patients with AF and } \\
\text { HFrEF to improve symptoms and } \\
\text { cardiac function when } \\
\text { tachycardiomyopathy is suspected. }\end{array}$} & \multirow[t]{2}{*}{ Ila } \\
\hline $\begin{array}{l}\text { - Should be considered in selected AF } \\
\text { patients with HFrEF to improve } \\
\text { survival and reduce HF hospitalization. }\end{array}$ & Ila & & \\
\hline
\end{tabular}


Table 1 (continued)

\begin{tabular}{|c|c|c|c|}
\hline \multicolumn{4}{|l|}{ Techniques and technologies } \\
\hline $\begin{array}{l}\text { Complete electrical isolation of the } \\
\text { pulmonary veins is recommended } \\
\text { during all AF catheter-ablation } \\
\text { procedures. }\end{array}$ & 1 & $\begin{array}{l}\text { Catheter ablation should target } \\
\text { isolation of the pulmonary veins using } \\
\text { radiofrequency ablation or cryothermy } \\
\text { balloon catheters. }\end{array}$ & IIa \\
\hline $\begin{array}{l}\text { If patient has a history of CTI- } \\
\text { dependent atrial flutter or if typical } \\
\text { atrial flutter is induced at the time of } \\
\text { AF ablation, delivery of a CTI lesion } \\
\text { may be considered. }\end{array}$ & $\mathrm{IIb}$ & $\begin{array}{l}\text { Ablation of common atrial flutter } \\
\text { should be considered to prevent } \\
\text { recurrent flutter as part of an AF } \\
\text { ablation procedure if documented or } \\
\text { occurring during the AF ablation. }\end{array}$ & Ila \\
\hline \multicolumn{4}{|c|}{ Lifestyle modification and other strategies to improve outcomes of ablation } \\
\hline $\begin{array}{l}\text { Weight loss is recommended in obese } \\
\text { patients with AF, particularly those } \\
\text { who are being evaluated to undergo } \\
\text { AF ablation. }\end{array}$ & 1 & $\begin{array}{l}\text { In obese patients with AF, weight loss } \\
\text { together with management of other } \\
\text { risk factors should be considered to } \\
\text { reduce AF burden and symptoms. }\end{array}$ & Ila \\
\hline \multicolumn{4}{|c|}{ Recommendations for stroke risk management peri-cardioversion } \\
\hline $\begin{array}{l}\text { In patients with AF undergoing } \\
\text { cardioversion, NOACs are } \\
\text { recommended with at least similar } \\
\text { efficacy and safety as warfarin. }\end{array}$ & 1 & $\begin{array}{l}\text { Anticoagulation with heparin or a } \\
\text { NOAC should be initiated as soon as } \\
\text { possible before every cardioversion of } \\
\text { AF or atrial flutter. }\end{array}$ & Ila \\
\hline \multicolumn{4}{|c|}{ Recommendations for stroke risk management peri-catheter ablation } \\
\hline $\begin{array}{l}\text { After AF catheter ablation, it is } \\
\text { recommended that: } \\
\text { - Systemic anticoagulation with } \\
\text { warfarin or a NOAC is continued for at } \\
\text { least } 2 \text { months post ablation, and } \\
\text { - Long-term continuation of systemic } \\
\text { anticoagulation beyond } 2 \text { months post } \\
\text { ablation is based on the patient's } \\
\text { stroke risk profile and not on the } \\
\text { apparent success or failure of the } \\
\text { ablation procedure. }\end{array}$ & 1 & $\begin{array}{l}\text { All patients should receive oral } \\
\text { anticoagulation for at least } 8 \text { weeks } \\
\text { after catheter ablation. }\end{array}$ & Ila \\
\hline \multicolumn{4}{|c|}{ Recommendations for long-term antiarrhythmic drugs } \\
\hline $\begin{array}{l}\text { Amiodarone is recommended for long- } \\
\text { term rhythm control in all AF patients, } \\
\text { including those with HFrEF. However, } \\
\text { owing to its extracardiac toxicity, other } \\
\text { AADs should be considered first } \\
\text { whenever possible. }\end{array}$ & 1 & $\begin{array}{l}\text { Amiodarone is more effective in } \\
\text { preventing } A F \text { recurrences than other } \\
A A D \text {, but extracardiac toxic effects are } \\
\text { common and increase with time. For } \\
\text { this reason, other AAD should be } \\
\text { considered first. }\end{array}$ & Ila \\
\hline \multicolumn{4}{|c|}{$\begin{array}{l}\text { Recommendations for lifestyle interventions and management of risk factors and concomitant } \\
\text { diseases in patients with AF }\end{array}$} \\
\hline $\begin{array}{l}\text { Attention to good BP control is } \\
\text { recommended in AF patients with } \\
\text { hypertension to reduce AF recurrences } \\
\text { and risk of stroke and bleeding. }\end{array}$ & 1 & $\begin{array}{l}\text { BP control in anticoagulated patients } \\
\text { with hypertension should be } \\
\text { considered to reduce the risk of } \\
\text { bleeding }\end{array}$ & Ila \\
\hline $\begin{array}{l}\text { Physical activity should be considered } \\
\text { to help prevent AF incidence or } \\
\text { recurrence, with the exception of } \\
\text { excessive endurance exercise, which } \\
\text { may promote AF. }\end{array}$ & Ila & $\begin{array}{l}\text { Moderate regular physical activity is } \\
\text { recommended to prevent AF, while } \\
\text { athletes should be counselled that } \\
\text { long-lasting intense sports } \\
\text { participation can promote AF }\end{array}$ & $\mathrm{I}$ \\
\hline $\begin{array}{l}\text { Optimal management of OSA may be } \\
\text { considered, to reduce AF incidence, AF } \\
\text { progression, AF recurrences, and } \\
\text { symptoms. }\end{array}$ & IIb & $\begin{array}{l}\text { OSA treatment should be optimized to } \\
\text { reduce } A F \text { recurrences and improve } A F \\
\text { treatment results. }\end{array}$ & Ila \\
\hline \multicolumn{4}{|c|}{ Recommendations for stroke prevention in $\mathrm{AF}$ patients after $\mathrm{ICH}$} \\
\hline $\begin{array}{l}\mathrm{n} \text { AF patients at high risk of ischaemic } \\
\text { stroke, (re-)initiation of OAC, with } \\
\text { preference for NOACs over VKAs in } \\
\text { NOAC-eligible patients, should be } \\
\text { considered in consultation with a } \\
\text { neurologist/ stroke specialist after: } \\
\text { - A trauma-related ICH } \\
\text { - Acute spontaneous ICH (which } \\
\text { includes subdural, subarachnoid, or } \\
\text { intracerebral haemorrhage), after } \\
\text { careful consideration of risks and } \\
\text { benefits }\end{array}$ & Ila & $\begin{array}{l}\text { After ICH oral anticoagulation in } \\
\text { patients with AF may be reinitiated } \\
\text { after } 48 \text { weeks provided the cause of } \\
\text { bleeding or the relevant risk factor has } \\
\text { been treated or controlled. }\end{array}$ & $\mathrm{IIb}$ \\
\hline \multicolumn{4}{|l|}{ Recommendations for postoperative $\mathrm{AF}$} \\
\hline $\begin{array}{l}\text { Long-term OAC therapy to prevent } \\
\text { thrombo-embolic events may be } \\
\text { considered in patients at risk for stroke } \\
\text { with postoperative AF after cardiac } \\
\text { surgery, considering the anticipated } \\
\text { net clinical benefit of OAC therapy and } \\
\text { informed patient preferences. }\end{array}$ & $\mathrm{IIb}$ & $\begin{array}{l}\text { Long-term anticoagulation should be } \\
\text { considered in patients with AF after } \\
\text { cardiac surgery at risk for stroke, } \\
\text { considering individual stroke and } \\
\text { bleeding risk. }\end{array}$ & Ila \\
\hline
\end{tabular}


Table 1 (continued)

$A A D$ antiarrhythmic drug, $A F$ atrial fibrillation, $B P$ blood pressure, $C T I$ cavotricuspid isthmus, $H F r E F$ heart failure with reduced ejection fraction, $I C H$ intracranial haemorrhage, INR international normalized ratio, $L V$ left ventricular, $L V E F$ left ventricular ejection fraction, NOAC non-vitamin $\mathrm{K}$ antagonist oral anticoagulant, $O A C$ oral anticoagulant or oral anticoagulation, PVI pulmonary vein isolation, TTR time in therapeutic range, $V K A$ vitamin $\mathrm{K}$ antagonist

${ }^{\mathrm{a} C l a s s}$ of recommendation
A screening program is accepted as efficient if it shows high sensitivity and can be carried out with low costs and risks. There are several screening tools in use for AF detection which are quite comparable in terms of their sensitivity, specificity and ease of application. Pulse palpation is a traditional and proven to be effective method for AF screening in older adults [20]. Oscillometric blood pressure monitors and smartphone applications reported to have higher sensitivity and specificity values, although the validation studies are conducted in small number of participants [21, 22]. There are also single-lead handheld devices that provide an ECG strip, which offers an advantage of confirmation of diagnosis with an ECG recording. These devices also reported to be very effective and have been widely used in AF screening studies [23, 24]. Wearable continuous ECG monitors have been demonstrated to be well tolerated and to increase AF detection tenfold, compared with oscillometric screening with a BP monitor [25].

All of these screening methods seem advantageous in older adults in terms of being practical, as patients remain seated, pass through brief measurements and do not need to undress. However, they also bring some disadvantages. Pulse palpation is the tool of choice for opportunistic screening due to its high sensitivity and cost effectiveness. Unfortunately, pulse is infrequently assessed in routine care. Cardiac auscultation can be the other option for detecting irregular heartbeats, but it is also less frequently preferred. There are several applications in use, however, most of them are not clinically validated. In addition, some of them require a noise-free trace for optimal performance. Furthermore, although they provide high sensitivity, their specificity is lower which can cause anxiety, create extra work and cost verifying diagnosis with an ECG [26]. Although the interest of the older population in technology has increased in recent years, the rate of use of smart phones or other devices with advancing age has not been proven yet. This makes the self-initiating, telemedical or wearable-based screening of AF currently not realistic, especially in oldest-old, cognitively impaired and very frail individuals. Hence, the optimum choice of AF screening tool is still a debate and mostly depends on patient profile and screening setting.

Another controversy regarding AF screening in older adults is which strategy of screening is more effective. According to a recent meta-analysis, there was no statistically significant difference between opportunistic (offered as part of a routine medical evaluation) and systematic (general or targeted screening of a high-risk population) screening [27]; yet, opportunistic screening is likely to be more cost-effective [28]. Settings that have been used effectively include community-based and others based in primary care, specialist practices, general or specialist clinics or pharmacies [29]. Indeed, primary care physicians have the potential to be at the forefront in screening programs. One of the biggest challenges about the settings is ensuring the link for referral to confirm diagnosis and establish proper work-up. In terms of providing a direct link with diagnosis, treatment and follow-up, primary care and outpatient clinics seem the most advantageous. In fact, health resources vary widely between countries and health systems. Therefore, the setting and strategy for screening should be country and healthsystem specific [29].

In this context, the best available evidence suggests that opportunistic screening of AF in older population is costeffective and should be performed. Older AF patients without cognitive impairment can be educated for checking their pulses intermittently, as self-detection of AF through pulse palpation was shown feasible in older adults [30]. Annual events (like influenza vaccination) can be a good opportunity for screening in this particular population $[31,32]$. The introduction of health checks including AF screening in general practice, and obligation of presenting practice reports (like the General Practice contract developed in 1990 in England) [33], may increase detection of AF. In addition to primary health care workers, staff working in secondary and tertiary health care units dealing with older adults, and also nursing home staff should be educated for importance of AF detection and ECG interpretation in a routine basis. In addition to opportunistic screening, systematic screening programs for patients aged $\geq 75$ years should be considered, since a significant number of this age group are vulnerable to AF outcomes due to their comorbidities, frailty, and cognitive impairments [1].

\section{Patients' global health status}

Patients with AF in clinical practice are older, have higher disease burden and are more frequently affected by functional limitations and dementia than those enrolled in RCTs [34]. Moreover, direct oral anticoagulants (DOACs) trials as well as observational studies did not consider geriatric 
syndromes such as frailty, cognitive impairment and functional dependence, which have been demonstrated to influence physicians' decision about DOACs use in older persons [34]. Therefore, beyond conventional embolic and bleeding risk scores, a decision-making guidance that incorporates factors such as frailty and dementia would be more helpful in determining the therapeutic approach. Indeed frailty, dementia and disability are among the most commonly cited reasons for OAT under-prescription, although evidence to support this decision is controversial [4].

\section{Frailty}

It has been reported that cardiologists subjectively identify frailty in the presence of problems in motility, cognition, malnutrition and sarcopenia [35]. In this context, frail and frailty are terms frequently used to label some older person on the basis of a subjective mix of disease burden, poor health status and cognitive or functional impairment. In the wide armamentarium of frailty tools, there are two basic conceptualizations of frailty. The Cardiovascular Health Study (CHS)-derived frailty "phenotype" identifies a sarcopenia-dependent model of frailty, which is diagnosed when at least three of five criteria among slow gait speed, low physical activity, unintentional weight loss, self-reported exhaustion and muscle weakness are recognized. In the seminal paper by Fried et al. this frailty phenotype was demonstrated to be associated with several adverse clinical outcomes, including worsening mobility and disability, hospitalizations and mortality over 7 years in communitydwelling older persons [36]. In recent years, several other tools have been proposed to identify this frailty phenotype, including the Simplified Fried test [37], the Short Physical Performance Battery (SPPB) [38], the $5 \mathrm{~m}$ gait speed [39], the Study of Osteoporotic Fractures (SOF) index [40, 41], the simple Frail Scale [42] and the SARC-F questionnaire [43]. A quite different approach to frailty conceptualization was developed by Rockwood et al. with the Canadian Study of Health and Aging (CSHA)-derived Frailty Index (FI) [44]. This is a 70-item form based on the accumulation of deficits (including functional limitations and disabilities, cognitive and sensory impairment, psychosocial variables and number of diseases), and its score is associated with increased probability of short-term risk of institutionalization, mortality and hospitalization. These authors further developed the seven-point Clinical Frailty Scale (CFS, a semi-quantitative eye-ball global judgement of frailty or vulnerability), which proved to be correlated with the FI and associated with increased risk of mortality and institutionalization [45]. The Multidimensional Prognostic Index (MPI) [46] (which is derived by a formal CGA through the inclusion of functional cognitive, nutritional and comorbidity scores and social support network) has also been demonstrated to be predictive of mortality and adverse clinical outcomes [47, 48].

The ESC guidelines for the diagnosis and management of AF (section 11.13) [1] state that "frailty, comorbidities, and increased risk of falls do not outweigh the benefits of OAT". However, despite we can concur with this simple statement, OAT prescription in older AF patients yet remains a troublesome decision, and persisting uncertainties are well represented by the current underuse of appropriate OAT in frail older patients with AF, despite their increased risk of embolic stroke and death [15, 34, 49]. Wilkinson et al recently suggested that "The lack of evidence to guide optimal care for patients with $\mathrm{AF}$ and frailty might in part explain the gap between current guidelines and clinical practice in management of these patients" [7].

Chronological age per se is not an acceptable criterion to guide clinical decision making, as convincingly demonstrated during the SARS-Cov-2 pandemic [50]. As both the CGA and the MPI are time-demanding procedures in daily clinical practice, it is difficult to implement them systematically in cardiology or general internal wards. In the quest for an easier alternative to this complex assessment, "frailty" appeared as a captivating surrogate. However, the growing number of frailty tools available, and the limited consensus on how to define and measure this complex state have generated confusion in several clinical settings, including the persistent uncertainties around the clinical benefit of OAT in frail older patients. We argue that most of these uncertainties might originate from the different clinical implications linked to the adoption of different frailty tools. Indeed, albeit under the same definition of "frailty", the two basic different conceptualizations (frailty phenotype vs accumulation of deficits) recognize different individuals and generate different clinical and prognostic implications. Whereas the CHS-frailty phenotype identifies patients at risk of adverse clinical outcomes in the presence of stressors [36], both the CFS and the FI recognize patients with global poor health status and with limited survival [36, 51-55]. Therefore, it is not surprising that using different tools to recognize "frailty" may identify older persons with rather different health status and residual life-span, thereby leading to discordant conclusions in many clinical settings, including AF [34, 56], and may generate confusion among expertise areas outside geriatrics.

Although a recent systematic review and meta-analysis on the management of AF for older persons with frailty concluded that "frailty is highly prevalent and associated with adverse clinical outcomes, and that there is a lack of evidence on the interaction of frailty and OAT with clinical outcomes to guide optimal care in this setting" [7], on the basis of current evidence it seems reasonable that older persons with AF and the "frail phenotype" might be considered for OAT, because of an expected net clinical benefit 
[34, 56-60], whereas at the moment there is scant, if any, evidence of benefit in those with severe frailty according to the FI/CFS, who are also more frequently denied OAT [7, $61,62]$.

\section{Cognitive impairment and falls}

Within the frame of the increasing exploitation of the concept of multidimensional frailty [63], particular attention should be offered to the bidirectional effects of cognitive decline and AF. If, in fact, AF-related stroke predisposes to dementia, there is an association between AF and dementia independent of stroke which demands a great deal of attention when managing older patients. Usually, the focus of healthcare practitioners concentrates on new-onset dementia, as about one-third of all stroke patients develop the condition within 5 years and AF patients have a 2.7-fold dementia risk after stroke $[64,65]$. Two meta-analyses revealed $\approx$ $30 \%$ increased risk of dementia in AF after adjustment for cerebrovascular events $[65,66]$. Furthermore, AF is related to cognitive impairment or dementia in younger ages [67]. In these studies, no brain imaging was performed to rule out clinically silent strokes as the underlying pathophysiology. In a case-referent study, which included magnetic resonance imaging brain imaging, stroke-free individuals with AF showed difficulties in learning, memory, attention and executive function compared with healthy referents [68]. Nonischemic mechanisms include cerebral hypoperfusion, vascular inflammation and genetic factors. Cerebral hypoperfusion and hypoxia have been demonstrated to be associated with increasing AF burden, and may be further worsened by concomitant heart failure with reduced ejection fraction [69-71]. There is growing evidence that implementing use of DOACs and maintenance of sinus rhythm after cardioversion or catheter ablation, may reduce the risk of cognitive decline [72-75].

While the mechanisms of AF-related cognitive impairment are multiple, interrelated and strongly associated to age-related changes [76-78], their consideration is essential in the management of older AF patients. As a consequence, a cognitive screening should be part of the routine evaluation of AF patients, especially in advanced age. However, as in turn the diade cognitive impairment-AF in the context of the heart-brain syndrome is chacterized by a complex interaction of several interwoven factors-including functional performance, psychosocial aspects, multimorbidity and polypharmacy-, a multidomain screening of the patient followed by a CGA in comanagement with the geriatrician appears to be the best available option to disentangle complexity and implement patient-centered, goal-oriented, value-based care in real life [79, 80]. Within a targeted CGA, a formal cognitive assessment would be helpful in AF patients, and cognitive impairment at mild-to moderate stage should not be viewed as a general contraindication to OAT, especially if well-managed from a logistically point of view. On the contrary, the appropriate management of AF has been consistently shown to improve cognitive performance $[72,73]$. Similarly to cognitive impairment, predisposition to falls is common in frail patients, and is often perceived as an important issue in starting OAT. Patients on OAT at high risk of falls do not consistently have a significantly increased risk of major bleedings [34]. While a multidimensional frailty assessment with screening of cognitive and gait/motoric functions is helpful to disclose important components of clinical decision making, current guidelines do not require fall risk estimation in candidates to OAT. As in the presence of cognitive impairment, the risk of fall should not be considered per se as a contraindication to the use of DOACs of general AF management. On the contrary, gait disturbances arising from cerebral blood perfusion and orthostatic deregulation might considerably benefit from prompt diagnosis and management of AF.

\section{Comorbidities and bleeding risk}

Older patients with AF are at risk of stroke and thromboembolism; therefore, planning a proper anticoagulant treatment soon after the diagnosis is essential. Unfortunately, advancing age is also associated with increased bleeding risk [81]. In this context, the bleeding risk (usually assessed through the HAS-BLED score) should not discourage physicians from prescribing OAT in patients with high risk of stroke, but rather prompt them to take action on controlling the modifiable bleeding risk factors and establishing a stricter and more frequent follow-up program [1]. Furthermore, these embolic and bleeding scores should be re-checked periodically in all AF patients [1].

Although previous bleeding events do not represent an absolute contraindication to OAT, there are several clinical situations which deserve a careful assessment in older AF patients. Older AF patients with spontaneous bleeding during OAT interruption, or unidentifiable or not treatable site of bleeding, or with recurrent bleeding from multiple angiodysplasias in the gastrointestinal tract, should be carefully assessed about the opportunity of withholding OAT [82]. Although several observational cohort studies suggest a survival and thromboembolic benefit in those who restarted OAT after major bleeding (MB) events [83, 84], clinicians should also consider that AF patients aged 80 years or older with a previous major gastrointestinal bleeding experience the greatest mortality (roughly $45 \%$ and $65 \%$ at 2 and 5 years, respectively) [85]; therefore, shared decision-making on the basis of the 
Table 2 Dose adjustment of direct thrombin inhibitor and oral factor Xa inhibitors for stroke prevention in patients with nonvalvular atrial fibrillation and specific conditions, according to the European Medicines Agency summary of product characteristics

\begin{tabular}{|c|c|c|c|c|}
\hline & Rivaroxaban $\neq$ & Apixaban $\mathbb{I}$ & Edoxaban $^{\wedge}$ & Dabigatran \\
\hline Full dose & $20 \mathrm{mg}$ OD & $5 \mathrm{mg}$ BID & $60 \mathrm{mg}$ OD & $150 \mathrm{mg}$ BID \\
\hline Age $\geq 80$ years & $20 \mathrm{mg}$ OD & $2.5 \mathrm{mg}$ BID if another criterion* & $60 \mathrm{mg}$ OD & $110 \mathrm{mg}$ BID \\
\hline Age $75-79$ years & $20 \mathrm{mg}$ OD & $5 \mathrm{mg}$ BID & $60 \mathrm{mg}$ OD & $110 \mathrm{mg}$ BID for consideration \\
\hline Body weight $\leq 60 \mathrm{~kg}$ & $20 \mathrm{mg}$ OD & $2.5 \mathrm{mg}$ BID if another criterion * & $30 \mathrm{mg}$ OD & - \\
\hline $\mathrm{SerCr} \geq 1.5 \mathrm{mg} / \mathrm{l}$ & - & $2.5 \mathrm{mg}$ BID if another criterion* & - & - \\
\hline $\mathrm{CrCl} 30-49 \mathrm{ml} / \mathrm{min}$ & $15 \mathrm{mg}$ OD & $5 \mathrm{mg}$ BID & $30 \mathrm{mg}$ OD & $110 \mathrm{mg}$ BID for consideration \\
\hline $\mathrm{CrCl} 15-29 \mathrm{ml} / \mathrm{min}$ & $15 \mathrm{mg}$ OD & $2.5 \mathrm{mg}$ BID & $30 \mathrm{mg}$ OD & Not recommended \\
\hline $\mathrm{CrCl}<15 \mathrm{ml} / \mathrm{min}$ & Not recommended & Not recommended & Not recommended & Not recommended \\
\hline \multicolumn{5}{|l|}{ Concomitant therapy: } \\
\hline Dronedarone & Not recommended & - & $30 \mathrm{mg}$ OD & Not recommended \\
\hline Cyclosporine & - & - & $30 \mathrm{mg}$ OD & Not recommended \\
\hline Erythromycin & $20 \mathrm{mg}$ OD & - & $30 \mathrm{mg}$ OD & - \\
\hline Ketoconazole & Not recommended & Not recommended & $30 \mathrm{mg}$ OD & Not recommended \\
\hline $\begin{array}{l}\text { HIV protease inhibitors } \\
\text { (e.g., ritonavir) }\end{array}$ & Not recommended & Not recommended & - & Not recommended \\
\hline Verapamil & - & $5 \mathrm{mg}$ BID & $60 \mathrm{mg}$ OD & 110 mg BID \\
\hline
\end{tabular}

$O D$ once a day, $B I D$ two times a day, $\mathrm{CrCl}$ creatinine clearance, $\mathrm{HIV}$ human immunodeficiency virus

$\neq$ https://www.ema.europa.eu/en/medicines/human/EPAR/xarelto

${ }^{\text {Ih }}$ https://www.ema.europa.eu/en/medicines/human/EPAR/eliquis

^https://www.ema.europa.eu/en/medicines/human/EPAR/lixiana

expected net clinical benefit is strongly advisable in these circumstances.

\section{Physicians' attitudes in prescribing OAT}

Prescription of OAT to older AF patients is a more complex clinical decision than a simple calculation of cardio-embolic and bleeding risk scores. Clinicians are well aware that some or most of their older AF patients may have limited residual life-span because of a relevant burden of pathologies and/ or geriatric syndromes. Indeed, whereas in phase III DOAC trials all-cause mortality was $4.7 \%$ year, with cardiac death contributing for $46 \%$ of deaths [86], real-world observational studies depict a different scenario. Among 186,461 Medicare beneficiaries (mean age 79.5 years) with AF, mortality was by far the most frequent major clinical events (occurring in $19.5 \%$ at 1 year and $48.8 \%$ at 5 years) [85]. Although several retrospective observational cohort studies demonstrated significant reduction of all-cause mortality in older patients treated with DOACs, regardless of poor health, functional conditions and multidimensional frailty, in most of these studies the mortality benefit was not accounted for by a significant reduction of stroke, suggesting that at least in part this mortality benefit might represent a selection bias (that is, OAT is prescribed to those perceived with longer survival). In this context, implementation of standardized tools described above to evaluate short-term mortality in older
AF patients might assist clinicians to address this therapy to those who may derive some benefit in their residual lifespan. The EUROSAF (European Study of Older Subjects with Atrial Fibrillation) project has begun to better accompany the daily clinical choice of managing OAT in older people [87]. EUROSAF is an observational study aimed at assessing the effectiveness and risks of anticoagulant therapy in frail older subjects with AF, stratified by the presence of frailty using the above described MPI $[63,87]$. Some preliminary data suggest that almost half of these patients are not treated with OAT, particularly if they are frail according to the MPI values [88]. Future data regarding the effect of anticoagulants (newer and older) could be important to see if frailty can be a significant determinant in mortality and cardiovascular events in people treated or not with OAT. In this context, the role of the CGA and its derivatives with high prognostic value such as the MPI, seems to be a crucial driver in taking clinical decisions in the frame of practical algorithms to be used in frail multi-morbid and poly-treated older patients with AF.

Unfortunately, uncertainties do not finish when coming to the decision to prescribe OAT. The recent 2020 ESC guidelines recommend use of DOACs in preference to VKA, except for patients with prosthetic mechanical heart valves and moderate to severe mitral valve stenosis [1]. Several DOACs rankings [89-92] and expert opinions [93-96] have been published to assist physicians to select the DOAC 
according to individual patient's characteristics. Apixaban has been demonstrated to have an excellent safety-efficacy balance, and suggested as a reasonable first choice either in older patients or in subjects with chronic renal failure [95]. The recently updated 2019 American Geriatrics Society Beers criteria recommend a cautious use of dabigatran and rivaroxaban in AF patients aged $\geq 75$ years because of greater risk of gastrointestinal bleeding [97]. In a recent report from the Fit-fOR-The-Aged (FORTA) classification (evaluating benefit, risk and appropriateness of drugs for older patients in everyday clinical settings), Apixaban was labelled A among OATs, meaning it was seen as the drug with the most favorable risk/benefit ratio in older patients [98].

These medications are fixed-dose oral regimens available in two different dose options, which have been variously named (standard, full or higher dose, and reduced or lower dose); anyway, dose prescription should be in keeping with drug-specific dosing guidelines (Table 2). However, as some clinicians get into difficulties in prescribing OAT to these complex older patients, many others also struggle with using DOAC recommended doses in this population. Indeed, several studies from different settings and countries consistently reported high prevalence of inappropriate DOAC dosing, with inappropriate reduced dosing being largely prevalent, particularly in older patients [99-102].

In a recent review about the pros and cons of inappropriate underdosing of oral Factor Xa activated Inhibitors (oFXaIs) [103] we demonstrated that although some underdosing may be ascribed to involuntary errors, a substantial proportion of it might reflect an intentional "cautious" approach to DOAC use in selected patients. Notably, very advanced age, female gender, presence of CKD, higher embolic and bleeding risk, previous bleeding or perceived high risk of bleeding, and concomitant use of antiplatelet drugs or nonsteroidal anti-inflammatory drugs (NSAIDs) were demonstrated to be associated with underdosing [103]. However, current evidence suggest that patients' characteristics rather than OAT intensity are associated with the risk of bleeding events, as suggested by the observation that the rates of MB in RCTs were higher among patients treated with oFXaIs at reduced dose than in those receiving full dose [104]. Moreover, real-life studies did not demonstrate a net clinical benefit by inappropriate underdosing of oFXaIs, but rather an increased risk of adverse events, including hospitalizations for cardiovascular causes and stroke, without a significant reduction of bleeding events [103].

In this context, a potential novel therapeutic approach in older AF frail patients came from the recently published Edoxaban Low-Dose for Elder Care Atrial Fibrillation Patients (ELDERCARE-AF), which compared a oncedaily $15-\mathrm{mg}$ dose of edoxaban with placebo in 984 Japanese patients (mean age 86.6 years, $57.4 \%$ female) who had nonvalvular AF and in whom standard OAT was not recommended for at least one of the following reasons: a low creatinine clearance (15-30 $\mathrm{ml}$ per min), a history of bleeding from a critical area or organ or gastrointestinal bleeding, low body weight ( $\leq 45 \mathrm{~kg}$ ), continuous use of NSAIDs, or current use of an antiplatelet drug [92]. Among the 681 patients who completed the trial the annualized rate of stroke or systemic embolism and MB were $2.3 \%$ vs $6.7 \%(p<0.001)$, and $3.3 \%$ vs $1.8 \%(p=0.09)$, in the edoxaban vs the placebo group, respectively, without substantial between-group difference in death from any cause [105]. These encouraging findings for a "humanitarian" OAT in the oldest patients should, however, be confirmed in other geographical areas and compared with appropriate DOAC doses before being considered an acceptable strategy in oldest patients.

Aspirin monotherapy was shown to be ineffective for stroke prevention in $\mathrm{AF}$, as well as associated with increased risk of stroke in older patients [106]. Since the landmark BAFTA study [107], OAT (including warfarin and DOACs) has been consistently demonstrated to outweigh aspirin in terms of clinical net benefit in older AF patients [108-110]. The AVERROES study clearly demonstrated that is no evidence of clinical benefit from prescribing antiplatelet therapy compared with Apixaban to older AF patients [111], and current European recommendations strongly advice against this practice [1,2], Likewise, use of dual antiplatelet therapy (DAPT) as an alternative to OAT is not recommended due to lower stroke prevention and similar bleeding rates [112].

Despite the increased bleeding risk, concomitant use of OAT and antiplatelets may become necessary due to interventions for coronary heart disease (CHD). Double antiplatelet therapy (DAPT) for at least 12 months is a routine treatment approach after percutaneous coronary interventions (PCI). However, in patients using OAT for AF, DAPT is recommended only for a short period (up to 1 month) for patients with acute CHD undergoing PCI. In this context, DOAC should be preferred, whenever possible, over warfarin. Following a short period of triple therapy, treatment with DOAC and $\mathrm{P} 2 \mathrm{Y}_{12}$ inhibitor should be continued for 12 months [1]. In selected patients, at very high thrombotic risk, triple therapy can sometimes be prolonged or single antiplatelet therapy continued along with DOAC for a longer period. This approach may seem appropriate due to the nature of thrombotic event or type of stent used. However, it may also become problematic and cause harm more than benefit, if the treatment approach is not based on a flexible, individualized approach for older patients. It should be kept in mind that antiplatelet treatment should be no longer continued if a patient is already using an OAT and has a stable CHD (which refers to acute coronary syndrome or PCI more than 12 months ago) or peripheral artery disease (PAD) (PAD requiring an intervention more than 1 month ago) $[113,114]$. 
Inappropriate medication use and polypharmacy, drug-drug and drug-disease interactions are common and should be taken into account in older patients treated with OAT [115]. Especially, warfarin users should be closely monitored for several drug, supplement and food interactions. NSAIDs should be avoided to reduce bleeding risk. Patients using concomitant OAT and antiplatelet therapy or corticosteroids should be given proton-pump inhibitors to avoid gastrointestinal bleedings [116, 117]. Main drug-drug interactions of DOACs involve P-glycoprotein (P-gp) and CYP3A4 CYP2Y2 competition and inhibition. Major contraindications for increased anticoagulant effect include concomitant use of anti-fungal drugs (itraconazole, ketoconazole, voriconazole, posaconazole) and quinidine virtually for all DOACs. Clarythromicin and erythromycin increase the anticoagulant effect in DOAC-treated patients, as well as amiodarone and dronedarone do in patients receiving dabigatran, rivaroxaban and edoxaban: dose-adjustment or use of a different DOAC should be considered in these circumstances [34]. There is evidence that concurrent use of amiodarone, rifampin, fluconazole and phenytoin in patients taking DOACs is associated with increased risk of MB compared with use of DOACs alone [118]. Furthermore, supplements commonly used in older adults (like ginkgo biloba) can cause serious bleedings when used concomitantly with OAT [114]. There is increasing evidence of several other drug interactions with potential clinical significance, including antineoplastic and antiepileptic drugs, of common use in older patients [2]. Therefore, use of DOACs in older patients mandate a careful evaluation of co-medications to optimize therapy and select the most appropriate drug and dose [34, 114].

\section{Conclusions and outlook}

As the world population grows in terms of size and age, the challenges related to diagnosis and management of AF are also expected to rise and pose healthcare practitioners the multifaceted challenges of complexity [119]. These include - far beyond organ-related medicine, multimorbidity and/or chronological age-aspects related to age-related physiological changes, physical and cognitive functional impairment as well as multidimensional frailty — a surrogate marker of biological age.

While geriatric medicine provides a series of screening methods targeting AF-influencing domains such as daily functions, social status, cognitive performance, mood and nutrition, evidence on the systematic comanaged adoption and interpretation of the CGA in older AF patients is lacking. This would be the necessary next step to improve recommendations and guidelines in the near future and the basis for implementation of CGA in clinical routine. CGAbased instruments, indeed, help to optimizing the patientcentered decisions in older AF patients. To inform this evidence and improve recommendations and guidelines in the near future, further systematic research is necessary to link results of the CGA to patient outcomes, treatment benefits/risk and clinical decision making.

\section{Expert opinion box}

- The large majority of AF patients are old-old and oldest-old. Recent DOACs RCTs, which demonstrated net clinical benefit over warfarin, mostly excluded oldestold, frail and cognitively impaired individuals.

- Although RCTs and observational studies demonstrated that DOACs provide clinical benefit over warfarin in the majority of older patients, there is scant evidence of net clinical benefit in frail, disabled and severely cognitive impaired patients

- Due to the lack of evidence, physicians' attitudes prevail, with high risk of undertreatment and, at the same time, of futile therapy. Decisions regarding AF treatment in older adults require a more specific and holistic approach; CGA, MPI and appropriate frailty tools may assist physicians in clinical decision making

- The risk of fall should not be considered a contraindication to the use of DOACs. High bleeding risk should not be interpreted as a contraindication to the use of OAT, but should direct physicians to assess and manage modifiable bleeding risk factors.

- Inappropriate DOAC dosing, especially inappropriate "reduced" dosing is highly prevalent in older adults, but real-life studies do not provide evidence of a net clinical benefit of this strategy. Use of antiplatelet therapy as an alternative to OAT is not recommended, due to lower stroke prevention and high bleeding rates.

- Opportunistic screening of AF in older population is cost-effective and should be performed by pulse palpation or ECG rhythm strip. Annual events (like influenza vaccination) can be a good opportunity for AF screening in older adults.

Funding Open Access funding enabled and organized by Projekt DEAL.

Availability of data and material Does not apply.

Code availability Does not apply. 


\section{Declarations}

Conflicts of interest Nothing to declare.

Ethical approval Not applicable.

Informed consent Not applicable.

Open Access This article is licensed under a Creative Commons Attribution 4.0 International License, which permits use, sharing, adaptation, distribution and reproduction in any medium or format, as long as you give appropriate credit to the original author(s) and the source, provide a link to the Creative Commons licence, and indicate if changes were made. The images or other third party material in this article are included in the article's Creative Commons licence, unless indicated otherwise in a credit line to the material. If material is not included in the article's Creative Commons licence and your intended use is not permitted by statutory regulation or exceeds the permitted use, you will need to obtain permission directly from the copyright holder. To view a copy of this licence, visit http://creativecommons.org/licenses/by/4.0/.

\section{References}

1. Hindricks G, Potpara T, Dagres N et al. (2020) ESC Guidelines for the diagnosis and management of atrial fibrillation developed in collaboration with the European Association of Cardio-Thoracic Surgery (EACTS). Eur Heart J 42:373498. https://www.escardio.org/Guidelines/Clinical-Practice-Guide lines/Guidelines-development/Writing-ESCGuidelines

2. Kirchhof P, Benussi S, Kotecha D et al (2016) 2016 ESC Guidelines for the management of atrial fibrillation developed in collaboration with EACTS. Eur Heart J 37:2893-2962. https://doi.org/10.1093/eurheartj/ehw210

3. Benjamin EJ, Levy D, Vaziri SM et al (1994) Independent risk factors for atrial fibrillation in a population-based cohort. The Framingham heart study. JAMA 271(11):840-844

4. Zathar Z, Karunatilleke A, Fawzy AM et al (2019) Atrial fibrillation in older people: concepts and controversies. Front Med. https://doi.org/10.3389/fmed.2019.00175

5. Krijthe BP, Kunst A, Benjamin EJ et al (2013) Projections on the number of individuals with atrial fibrillation in the European Union, from 2000 to 2060. Eur Heart J 34(35):27462751. https://doi.org/10.1093/eurheartj/eht280

6. Magnani JW, Wang N, Benjamin EJ et al (2016) Atrial fibrillation and declining physical performance in older adults: the health, aging, and body composition study. Circ Arrhythm Electrophysiol 9:e003525. https://doi.org/10.1161/CIRCEP. 115.003525.PMID:27052031;PMCID:PMC4826757

7. Wilkinson C, Todd O, Clegg A et al (2019) Management of atrial fibrillation for older people with frailty: a systematic review and meta-analysis. Age Ageing 48:196-203. https:// doi.org/10.1093/ageing/afy 180

8. Alonso A, Arenas-de-Larriva AP (2016) Atrial fibrillation, cognitive decline and dementia. Eur Cardiol. 11:49-53. https:// doi.org/10.15420/ecr.2016:13:2

9. Polidori MC (2021) Physiology of aging as a basis of complexity in aging medicine and geriatrics. In: Gu D, Dupre M (Eds) Ageing Medicine and Geriatrics. Polidori MC Section Ed. Encyclopedia of Gerontology and Population Aging. Springer

10. Caldeira D, Nunes-Ferreira A, Rodrigues R et al (2019) Nonvitamin $\mathrm{K}$ antagonist oral anticoagulants in elderly patients with atrial fibrillation: a systematic review with meta-analysis and trial sequential analysis. Arch Gerontol Geriatr 81(3):209214. https://doi.org/10.1016/j.archger.2018.12.013

11. ICH E7 Studies in support of special populations: geriatrics I European Medicines Agency. https://www.ema.europa.eu/ en/ich-e7-studies-support-special-populations-geriatrics. Accessed 16 Jan 2021

12. Hughey AB, Gu X, Haymart B et al (2018) Warfarin for prevention of thromboembolism in atrial fibrillation: comparison of patient characteristics and outcomes of the 'Real-World' Michigan Anticoagulation Quality Improvement Initiative (MAQI2) registry to the RE-LY, ROCKET-AF, and ARISTOTLE trials. J Thromb Thrombolysis 46(3):316-324

13. Bibas L, Levi M, Touchette $\mathbf{J}$ (2016) Implications of frailty in elderly patients with electrophysiological conditions. JACC Clin Electrophysiol 2(3):288-294. https://doi.org/10.1016/j. jacep.2016.04.013

14. Cruz-Jentoft AJ, Daragjati J, Fratiglioni L et al (2020) Using the Multidimensional Prognostic Index (MPI) to improve costeffectiveness of interventions in multimorbid frail older persons: results and final recommendations from the MPI_AGE European Project. Aging Clin Exp Res 32(5):861-868. https:// doi.org/10.1007/s40520-020-01516-0

15. Potpara TS, Mujovic N, Lip GYH (2020) Challenges in stroke prevention among very elderly patients with atrial fibrillation: discerning facts from prejudices. Europace 22:173-176

16. Marinigh R, Lip GYH, Fiotti N et al (2010) Age as a risk factor for stroke in atrial fibrillation patients. J Am Coll Cardiol $56: 827-837$

17. Boriani G, Laroche C, Diemberger I et al (2015) Asymptomatic atrial fibrillation: clinical correlates, management, and outcomes in the EORP-AF Pilot General Registry. Am J Med 128(5):509-18.e2

18. Turakhia MP, Shafrin J, Bognar K et al (2018) Estimated prevalence of undiagnosed atrial fibrillation in the United States. PLoS ONE 13(4):e0195088

19. Martinez C, Katholing A, Freedman SB (2014) Adverse prognosis of incidentally detected ambulatory atrial fibrillation. A cohort study. Thromb Haemost 112(2):276-286

20. Fitzmaurice DA, Hobbs FDR, Jowett $S$ et al (2007) Screening versus routine practice in detection of atrial fibrillation in patients aged 65 or over: cluster randomised controlled trial. Br Med J (Clin Res Ed) 335:383

21. Wiesel J, Arbesfeld B, Schechter D (2014) Comparison of the Microlife blood pressure monitor with the Omron blood pressure monitor for detecting atrial fibrillation. Am J Cardiol 114(7):1046-1048

22. McManus DD, Chong JW, Soni A et al (2016) PULSESMART: pulse-based arrhythmia discrimination using a novel smartphone application. J Cardiovasc Electrophysiol 27(1):51-57

23. Lowres N, Neubeck L, Salkeld G et al (2014) Feasibility and cost-effectiveness of stroke prevention through community screening for atrial fibrillation using iPhone ECG in pharmacies: the SEARCH-AF study. Thromb Haemost 111:1167-1176

24. Tieleman RG, Plantinga Y, Rinkes D et al (2014) Validation and clinical use of a novel diagnostic device for screening of atrial fibrillation. Europace 16:1291-1295

25. Gladstone DJ, Wachter R, Schmalstieg-Bahr K, SCREEN-AF Investigators and Coordinators et al (2021) Screening for atrial fibrillation in the older population: a randomized clinical trial. JAMA Cardiol. 24:e210038. https://doi.org/10.1001/jamacardio. 2021.0038

26. Freedman B (2016) Screening for atrial fibrillation using a smartphone: is there an app for that? J Am Heart Assoc 5:e00400 
27. Petryszyn P, Niewinski P, Staniak A et al (2019) Effectiveness of screening for atrial fibrillation and its determinants. A metaanalysis. PLoS ONE 14(3):e0213198

28. Mairesse GH, Moran P, Van Gelder IC, ESC Scientific Document Group et al (2017) Screening for atrial fibrillation: a European Heart Rhythm Association (EHRA) consensus document endorsed by the Heart Rhythm Society (HRS), Asia Pacific Heart Rhythm Society (APHRS), and Sociedad Latinoamericana de Estimulación Cardíaca y Electrofisiología (SOLAECE). Europace 19(10):1589-1623

29. Freedman B, Camm J, Calkins H, AF-Screen Collaborators et al (2017) AF-screen collaborators screening for atrial fibrillation: a report of the AF-SCREEN International Collaboration. Circulation 135(19):1851-1867

30. Jaakkola J, Vasankari T, Virtanen R et al (2017) Reliability of pulse palpation in the detection of atrial fibrillation in an elderly population. Scand J Prim Health Care 35(3):293-298

31. Orchard J, Lowres N, Freedman SB et al (2016) Screening for atrial fibrillation during influenza vaccinations by primary care nurses using a smartphone electrocardiograph (iECG): a feasibility study. Eur J Prev Cardiol 23(2 suppl):13-20

32. Proietti M, Mairesse GH, Goethals P, Belgian Heart Rhythm Week Investigators et al (2016) A population screening programme for atrial fibrillation: a report from the Belgian Heart Rhythm Week screening programme. Europace 18(12):1779-1786

33. Peckham S, Hann A, Kendall S et al (2017) Health promotion and disease prevention in general practice and primary care: a scoping study. Prim Health Care Res Dev 18(6):529-540

34. Bo M, Marchionni N (2020) Practical use of direct oral anticoagulants (DOACs) in the older person with atrial fibrillation. Eur J Intern Med 71:32-38. https://doi.org/10.1016/j.ejim. 2019.10.026

35. Fumagalli S, Potpara TS, Bjerregaard Larsen T et al (2017) Frailty syndrome: an emerging clinical problem in the everyday management of clinical arrhythmias. The results of the European Heart Rhythm Association survey. Europace 19(11):1896-1902. https://doi.org/10.1093/europace/eux288

36. Fried LP, Tangen CM, Walston J, Cardiovascular Health Study Collaborative Research Group et al (2001) Frailty in older adults: evidence for a phenotype. J Gerontol A Biol Sci Med Sci 56:M146-M156

37. Bahat G, llhan B, Tufan A et al (2020) Success of simpler modified frailty scale to predict mortality among nursing home residents. J Nutr Health Ageing

38. Guralnik JM, Ferrucci L, Simonsick EM et al (1995) Lowerextremity function in persons over the age of 70 years as a predictor of subsequent disability. N Engl J Med 332(9):556-561. https://doi.org/10.1056/NEJM199503023320902

39. Hardy SE, Perera S, Roumani YF et al (2007) Improvement in usual gait speed predicts better survival in older adults. $\mathbf{J}$ Am Geriatr Soc 55(11):1727-1734. https://doi.org/10.1111/j. 1532-5415.2007.01413.x

40. Chen X, Leng S, Mao G (2014) Frailty syndrome: an overview. Clin Interv Aging 9:433-441. https://doi.org/10.2147/ CIA.S45300

41. Junius-Walker U, Onder G, Soleymani D et al (2018) The essence of frailty: a systematic review and qualitative synthesis on frailty concepts and definitions. Eur J Intern Med 56:3-10. https://doi.org/10.1016/j.ejim.2018.04.023

42. Morley JE, Vellas B, van Kan AG et al (2013) Frailty consensus: a call to action. J Am Med Dir Assoc 14(6):392-397. https://doi.org/10.1016/j.jamda.2013.03.022

43. Bahat G, Ozkok S, Kilic C et al (2021) SARC-F questionnaire detects frailty in older adults. J Nutr Health Aging 25(4):448453. https://doi.org/10.1007/s12603-020-1543-9
44. Rockwood K, Wolfson C, McDowell I (2001) The Canadian Study of Health and Aging: organizational lessons from a national, multicenter, epidemiologic study. Int Psychogeriatr 13(Supp 1):233-237. https://doi.org/10.1017/S104161020 2008177

45. Rockwood K (2005) A global clinical measure of fitness and frailty in elderly people. Can Med Assoc J 173(5):489-495. https://doi.org/10.1503/cmaj.050051

46. Pilotto A, Addante F, Franceschi M et al (2010) Multidimensional Prognostic Index based on a comprehensive geriatric assessment predicts short-term mortality in older patients with heart failure. Circ Heart Fail 3(1):14-20. https://doi.org/10. 1161/CIRCHEARTFAILURE.109.865022

47. Pilotto A, Ferrucci L, Franceschi M et al (2008) Development and validation of a multidimensional prognostic index for oneyear mortality from comprehensive geriatric assessment in hospitalized older patients. Rejuvenation Res 11(1):151-161. https://doi.org/10.1089/rej.2007.0569

48. Pickert L, Meyer AM, Becker I et al (2021) Role of a multidimensional prognosis in-hospital monitoring for older patients with prolonged stay. Int J Clin Pract 6:e13989. https://doi.org/ 10.1111/ijcp.13989

49. Kloosterman M, Crijns HJGM, Van Gelder IC (2019) Rising prevalence of atrial fibrillation in the elderly population: new challenges of geriatric cardiology. Europace 21(10):1451-1453

50. Polidori MC, Sies H, Ferrucci L et al (2021) COVID-19 mortality as a fingerprint of biological age. Ageing Res Rev 67:101308. https://doi.org/10.1016/j.arr.2021.101308

51. Hoogendijk EO, Afilalo J, Ensrud KE et al (2019) Frailty: implications for clinical practice and public health. Lancet 394:1365-1375

52. Mitnitski AB, Mogilner AJ, Rockwood K (2001) Accumulation of deficits as a proxy measure of aging. Sci World 1:323-336

53. Song X, Mitnitski AB, Mac Knight C et al (2004) Assessment of individual risk of death using self-report data: an artificial neural network compared with a frailty index. J Am Geriatr Soc 52:1180-1184

54. Jones DM, Song X, Rockwood K (2004) Operationalizing a frailty index from a standardized comprehensive geriatric assessment. J Am Geriatr Soc 52:1929-1933

55. Dunlay SM, Manemann SM, Chamberlain AM et al (2015) Activities of daily living and outcomes in heart failure. Circ Heart Fail 8(2):261-267. https://doi.org/10.1161/circheartf ailure.114.001542

56. Villani ER, Tummolo AM, Palmer K et al (2018) Frailty and atrial fibrillation: a systematic review. Eur J Intern Med 56:33-38

57. Madhavan M, Holmes DN, Piccini JP, ORBIT AF Investigators et al (2019) Association of frailty and cognitive impairment with benefits of oral anticoagulation in patients with atrial fibrillation. Am Heart J 211:77-89

58. Gullón A, Formiga F, Díez-Manglano J, NONAVASC study group Vascular Risk Group of the Spanish Society of Internal Medicine et al (2019) Influence of frailty on anticoagulant prescription and clinical outcomes after 1-year follow-up in hospitalized older patients with atrial fibrillation. Intern Emerg Med 14:59-69

59. Mailhot T, McManus DD, Waring ME et al (2020) Frailty, cognitive impairment, and anticoagulation among older adults with nonvalvular atrial fibrillation. J Am Geriatr Soc 68:jgs.16756

60. Lip GYH, Keshishian AV, Kang AL et al (2020) Oral anticoagulants for nonvalvular atrial fibrillation in frail elderly patients: insights from the ARISTOPHANES study. J Intern Med 289:joim. 13140

61. Lefebvre MCD, St-Onge M, Glazer-Cavanagh M et al (2016) The effect of bleeding risk and frailty status on anticoagulation 
patterns in octogenarians with atrial fibrillation: The FRAIL-AF Study. Can J Cardiol 32(2):169-176

62. Wojszel ZB, Kasiukievicz A (2020) Determinants of anticoagulant therapy in atrial fibrillation at discharge from a geriatric ward: cross sectional study. J Thromb Thrombolysis 49:18-26

63. Pilotto A, Custodero C, Maggi S et al (2020) A multidimensional approach to frailty in older people. Ageing Res Rev 60:101047. https://doi.org/10.1016/j.arr.2020.101047

64. Poggesi A, Inzitari D, Pantoni L (2015) Atrial fibrillation and cognition: epidemiological data and possible mechanisms. Stroke 46:3316-3321. https://doi.org/10.1161/STROKEAHA. 115.008225

65. Kalantarian S, Stern TA, Mansour M et al (2013) Cognitive impairment associated with atrial fibrillation: a meta-analysis. Ann Intern Med 158:338-346. https://doi.org/10.7326/00034819-158-5-201303050-00007

66. Saglietto A, Matta M, Gaita F et al (2019) Stroke-independent contribution of atrial fibrillation to dementia: a meta-analysis. Open Heart 6:e00984. https://doi.org/10.1136/openhrt-2018000984164

67. Park H, Hildreth A, Thomson R et al (2007) Non-valvular atrial fibrillation and cognitive decline: a longitudinal cohort study. Age Ageing 36:157-163. https://doi.org/10.1093/ageing/afl16 4165

68. Knecht S, Oelschläger C, Duning T et al (2008) Atrial fibrillation in stroke free patients is associated with memory impairment and hippocampal atrophy. Eur Heart J 29:2125-2132. https://doi.org/ 10.1093/eurheartj/ehn341

69. Jefferson AL, Himali JJ, Beiser AS et al (2010) Cardiac index is associated with brain aging: the Framingham Heart Study. Circulation 122:690-697. https://doi.org/10.1161/CIRCULATIO NAHA.109.905091

70. Jefferson AL, Himali JJ, Au R et al (2011) Relation of left ventricular ejection fraction to cognitive aging (from the Framingham Heart Study). Am J Cardiol 108:1346-1351. https://doi.org/ 10.1016/j.amjcard.2011.06.056

71. Tilvis RS, Kähönen-Väre MH, Jolkkonen J et al (2004) Predictors of cognitive decline and mortality of aged people over a 10-year period. J Gerontol A Biol Sci Med Sci 59:268-274. https://doi. org/10.1093/gerona/59.3.m268

72. Friberg L, Rosenqvist M (2018) Less dementia with oral anticoagulation in atrial fibrillation. Eur Heart J 39:453-460. https:// doi.org/10.1093/eurheartj/ehx579

73. Kim D, Yang PS, Jang E et al (2021) Association of anticoagulant therapy with risk of dementia among patients with atrial fibrillation. Europace 23:184-195. https://doi.org/10.1093/europ ace/euaa192

74. Gardarsdottir M, Sigurdsson S, Aspelund T et al (2020) Improved brain perfusion after electrical cardioversion of atrial fibrillation. Europace 22:530-537. https://doi.org/10.1093/europace/euz336

75. Kim D, Yang PS, Sung JH et al (2020) Less dementia after catheter ablation for atrial fibrillation: a nationwide cohort study. Eur Heart J 41:4483-4493. https://doi.org/10.1093/eurheartj/ehaa726

76. Polidori MC, Marvardi M, Cherubini A et al (2001) Heart disease and vascular risk factors in the cognitively impaired elderly: implications for Alzheimer's dementia. Aging (Milano) 13(3):231-239

77. Polidori MC, Pientka L, Mecocci P (2012) A review of the major vascular risk factors related to Alzheimer's disease. J Alzheimers Dis 32(3):521-530. https://doi.org/10.3233/JAD-2012-120871

78. Polidori MC, Pientka L (2012) Bridging the pathophysiology of Alzheimer's disease with vascular pathology: the feed-back, the feed-forward, and oxidative stress. J Alzheimers Dis 28(1):1-9. https://doi.org/10.3233/JAD-2011-111034
79. Polidori et al (2018) Cognitive decline. In: Roller-Wirnsberger K, Singler K, Polidori MC (eds) Learning geriatric medicine. Springer

80. Polidori MC (2018) The comprehensive geriatric assessment in cognitive decline. In: Pilotto A, Martin FC (eds) comprehensive geriatric assessment. Springer

81. Selak V, Kerr A, Poppe K et al (2018) Annual risk of major bleeding among persons without cardiovascular disease not receiving antiplatelet therapy. JAMA 319:2507-2520. https:// doi.org/10.1001/jama.2018.8194

82. Halvorsen S, Storey RF, Rocca B, ESC Working Group on Thrombosis et al (2017) Management of antithrombotic therapy after bleeding in patients with coronary artery disease and/or atrial fibrillation: expert consensus paper of the European Society of Cardiology Working Group on Thrombosis. Eur Heart J 38:1455-1462. https://doi.org/10.1093/eurheartj/ehw454

83. Qureshi W, Mittal C, Patsias I et al (2014) Restarting anticoagulation and outcomes after major gastrointestinal bleeding in atrial fibrillation. Am J Cardiol 113(4):662-668. https://doi.org/ 10.1016/j.amjcard.2013.10.044

84. Staerk L, Lip GYW, Olesen JB et al (2015) Stroke and recurrent haemorrhage associated with antithrombotic treatment after gastrointestinal bleeding in patients with atrial fibrillation: nationwide cohort study. BMJ 351:h5876. https://doi.org/10.1136/bmj. h5876

85. Piccini JP, Hammill BG, Sinner MF et al (2014) Clinical course of atrial fibrillation in older adults: the importance of cardiovascular events beyond stroke. Eur Heart J 35:250-256

86. Gómez-Outes A, Lagunar-Ruíz J, Terleira-Fernández A-I et al (2016) Causes of death in anticoagulated patients with atrial fibrillation. J Am Coll Cardiol 68(23):2508-2521

87. Pilotto A, Maggi S, Polidori MC et al (2017) The European study of older subjects with atrial fibrillation (EUROSAF). Aim and study design. Eur Geriatr Med 8(suppl 1):S83

88. Veronese N, Argusti A, Canepa E et al (2018) Evaluating the effectiveness and risks of oral anticoagulant treatments in multimorbid frail older subjects with atrial fibrillation using the multidimensional prognostic index: the EURopean study of older subjects with atrial fibrillation EUROSAF. Eur Geriatr Med 9:149-154

89. Capranzano P, Miccichè E, D’Urso L et al (2013) Personalizing oral anticoagulant treatment in patients with atrial fibrillation. Expert Rev Cardiovasc Ther 11(8):959-973. https://doi.org/10. 1586/14779072.2013.818819

90. Guo L, Li S, Wang P et al (2017) Comparative efficacy of clinical events prevention of five anticoagulants in patients with atrial fibrillation (a network meta-analysis). Am J Cardiol 119(4):585593. https://doi.org/10.1016/j.amjcard.2016.11.006

91. Mueller T, Alvarez-Madrazo S, Robertson C et al (2019) Comparative safety and effectiveness of direct oral anticoagulants in patients with atrial fibrillation in clinical practice in Scotland. $\mathrm{Br}$ J Clin Pharmacol 85:422-431

92. Bo M, Grisoglio E, Brunetti E et al (2017) Oral anticoagulant therapy for older patients with atrial fibrillation: a review of current evidence. Eur J Intern Med 41:18-27

93. Lip GYH, Lane DA (2015) Matching the NOAC to the patient: remember the modifiable bleeding risk factors. $\mathrm{j}$ Am Coll Cardiol 66(21):2282-2284. https://doi.org/10.1016/j.jacc.2015.07.086

94. Shields AM, Lip GYH (2015) Choosing the right drug to fit the patient when selecting oral anticoagulation for stroke prevention in atrial fibrillation. J Intern Med 278(1):1-18. https://doi.org/10. 1111/joim. 12360

95. Diener H-C, Aisenberg J, Ansell J et al (2017) Choosing a particular oral anticoagulant and dose for stroke prevention in individual 
patients with non-valvular atrial fibrillation: part 1. Eur Heart $\mathbf{J}$ 38(12):852-859. https://doi.org/10.1093/eurheartj/ehv643

96. Diener H-C, Aisenberg J, Ansell J et al (2017) Choosing a particular oral anticoagulant and dose for stroke prevention in individual patients with non-valvular atrial fibrillation: part 2. Eur Heart J 38(12):860-868. https://doi.org/10.1093/eurheartj/ehw069

97. American Geriatrics Society Beers Criteria ${ }^{\circledR}$ Update Expert Panel (2019) American Geriatrics Society 2019 Updated AGS Beers Criteria ${ }^{\circledR}$ for potentially inappropriate medication use in older adults. J Am Geriatr Soc 67(4):674-694. https://doi.org/ $10.1111 /$ jgs. 15767

98. Wehling M, Collins R, Gil VM et al (2017) Appropriateness of oral anticoagulants for the long-term treatment of atrial fibrillation in older people: results of an evidence-based review and international consensus validation process (OAC-FORTA 2016). Drugs Aging 34(7):499-507. https://doi.org/10.1007/ s40266-017-0466-6

99. Sanghai S, Wong C, Wang Z et al (2020) Rates of potentially inappropriate dosing of direct-acting oral anticoagulants and associations with geriatric conditions among older patients with atrial fibrillation: the SAGE-AF Study. J Am Heart Assoc 9(6): $\mathrm{e} 014108$

100. Steinberg BA, Shrader P, Pieper K, Outcomes Registry for Better Informed Treatment of Atrial Fibrillation (ORBIT-AF) II Investigators et al (2018) Frequency and outcomes of reduced dose non-vitamin $\mathrm{K}$ antagonist anticoagulants: results from ORBITAF II (The Outcomes Registry for Better Informed Treatment of Atrial Fibrillation II). J Am Heart Assoc 7(4):7633

101. Viprey M, Jeannin R, Piriou V et al (2017) Prevalence of drugrelated problems associated with direct oral anticoagulants in hospitalized patients: a multicenter, cross-sectional study. J Clin Pharm Ther 42:58-63

102. Erdogan T, Erdogan O, Ozturk S et al (2021) Non-vitamin K antagonist oral anticoagulant use at doses inappropriately lower than recommended in outpatient older adults: a real-life data. Eur Geriatr Med. https://doi.org/10.1007/s41999-021-00452-0

103. Bo M, Corsini A, Brunetti E et al (2020) Off-label use of reduced dose direct oral factor Xa-inhibitors in subjects with atrial fibrillation: a review of clinical evidence. Eur Heart J Cardiovasc Pharmacother. https://doi.org/10.1093/ehjcvp/pvaa103

104. Wang KL, Lopes RD, Patel MR et al (2019) Efficacy and safety of reduced-dose non-vitamin $\mathrm{K}$ antagonist oral anticoagulants in patients with atrial fibrillation: a meta-analysis of randomized controlled trials. Eur Heart J 40(19):1492-1500

105. Okumura K, Akao M, Yoshida T et al (2020) Low-dose edoxaban in very elderly patients with atrial fibrillation. N Engl J Med 383:1735-1745

106. Själander S, Själander A, Svensson PJ et al (2014) Atrial fibrillation patients do not benefit from acetylsalicylic acid. Europace 16(5):631-638

107. Mant J, Hobbs FD, Fletcher K, BAFTA Investigators et al (2007) Midland Research Practices Network (MidReC). Warfarin versus aspirin for stroke prevention in an elderly community population with atrial fibrillation (the Birmingham Atrial Fibrillation Treatment of the Aged Study, BAFTA): a randomised controlled trial. Lancet 370(9586):493-503

108. Chan YH, See LC, Tu HT et al (2018) Efficacy and safety of apixaban, dabigatran, rivaroxaban, and warfarin in Asians with nonvalvular atrial fibrillation. J Am Heart Assoc 7(8):e008150
109. Patti G, Lucerna M, Pecen L et al (2017) Thromboembolic risk, bleeding outcomes and effect of different antithrombotic strategies in very elderly patients with atrial fibrillation: a sub-analysis from the PREFER in AF (PREvention oF Thromboembolic Events-European Registry in Atrial Fibrillation). J Am Heart Assoc 6(7):e005657

110. Ng KH, Hart RG, Eikelboom JW (2013) Anticoagulation in patients aged $\geq 75$ years with atrial fibrillation: role of novel oral anticoagulants. Cardiol Ther 2(2):135-149

111. Ng KH, Shestakovska O, Connolly SJ et al (2016) Efficacy and safety of apixaban compared with aspirin in the elderly: a subgroup analysis from the AVERROES trial. Age Ageing 45(1):77-83

112. ACTIVE Writing Group of the ACTIVE Investigators, Connolly S, Pogue J et al (2006) Clopidogrel plus aspirin versus oral anticoagulation for atrial fibrillation in the Atrial fibrillation Clopidogrel Trial with Irbesartan for prevention of Vascular Events (ACTIVE W): a randomized controlled trial. Lancet 367(9526): 1903-1912

113. Aboyans V, Ricco JB, Bartelink MEL, ESC Scientific Document Group et al (2018) 2017 ESC Guidelines on the Diagnosis and Treatment of Peripheral Arterial Diseases, in collaboration with the European Society for Vascular Surgery (ESVS): document covering atherosclerotic disease of extracranial carotid and vertebral, mesenteric, renal, upper and lower extremity arteries. Endorsed by: the European Stroke Organization (ESO) The Task Force for the Diagnosis and Treatment of Peripheral Arterial Diseases of the European Society of Cardiology (ESC) and of the European Society for Vascular Surgery (ESVS). Eur Heart J 39(9):763-816

114. Bahat G, Ilhan B, Erdogan T et al (2020) Turkish Inappropriate Medication use in the Elderly (TIME) criteria to improve prescribing in older adults: TIME-to-STOP/TIME-to-START. Eur Geriatr Med 11(3):491-498

115. Mangin D, Bahat G, Golomb BA et al (2018) International Group for Reducing Inappropriate Medication Use \& Polypharmacy (IGRIMUP): position statement and 10 recommendations for action. Drugs Aging 35(7):575-587. https://doi.org/10.1007/ s40266-018-0554-2

116. Abrignani MG, Gatta L, Gabrielli D et al (2021) Gastroprotection in patients on antiplatelet and/or anticoagulant therapy: a position paper of National Association of Hospital Cardiologists (ANMCO) and the Italian Association of Hospital Gastroenterologists and Endoscopists (AIGO). Eur J Intern Med 85:1-13. https://doi.org/10.1016/j.ejim.2020.11.014

117. Ray WA, Chung CP, Murray KT et al (2018) Association of oral anticoagulants and proton pump inhibitor cotherapy with hospitalization for upper gastrointestinal tract bleeding. JAMA 320(21):2221-2230

118. Chang SH, Chou IJ, Yeh YH et al (2017) Association Between use of non-vitamin $\mathrm{k}$ oral anticoagulants with and without concurrent medications and risk of major bleeding in nonvalvular atrial fibrillation. JAMA 318(13):1250-1259. https://doi.org/10. 1001/jama.2017.13883

119. Kornej J, Börschel CS, Benjamin EJ et al (2020) Epidemiology of atrial fibrillation in the 21st century: novel methods and new insights. Circ Res 127(1):4-20. https://doi.org/10.1161/CIRCR ESAHA. 120.316340

Publisher's Note Springer Nature remains neutral with regard to jurisdictional claims in published maps and institutional affiliations. 